\title{
An Analysis of the Learners' Factors in Second Language Teaching and Learning
}

\author{
Lili Zhao ${ }^{1}$ \\ ${ }^{1}$ Department of Foreign Language Teaching, Inner Mongolia University for the Nationalities, Tongliao, China \\ Correspondence: Department of Foreign Language Teaching, Inner Mongolia University for the Nationalities, \\ Tongliao, China. E-mail: lilingky@163.com
}

Received: October 1, 2015

Accepted: November 7, $2015 \quad$ Online Published: November 17, 2015

doi:10.5539/ijps.v7n4p130

URL: http://dx.doi.org/10.5539/ijps.v7n4p130

\begin{abstract}
This paper aims at exploring the influences that learner's factors have on second language teaching and learning. Firstly, this paper gives brief definitions of cognitive theory and the theory of behaviorism, which are relevant to learner's individual factors. And then a learner's most important factors such as motivation, aptitude and self-confidence are introduced to illustrate the influences these factors have made on second language learning and teaching. Some suggestions are given for English teaching and after a presentation of the taxonomy of language learning strategies, the training of language learning strategies is mentioned so as to throw light on the future work of language teaching and learning.
\end{abstract}

Keywords: learner's factors, cognition, learning strategies, teaching methods, behaviorism

\section{Introduction}

Learners' factors are gaining more and more attention in second language teaching and learning. Any problem of language teaching and language learning should be dealt with form the perspective of individual differences. Consideration of learners' factors with a combination of intelligence and nonintellectual factors should be taken in English teaching if the teacher wants to achieve better achievements. Therefore, teachers should pay attention to not only the development of students' intelligence, but the promotion and stimulation of students' affective factors so as to guide students to learn efficiently by making good use of their outstanding aspects of learners' factors. In the next section, after a statement of the theoretical background, the learners' factors involving motivation, aptitude and self-confidence are presented. After that, suggestions of the teaching methods concerning learners' motivation, aptitude and self-confidence are introduced. Accordingly, some important learning strategies such as cognitive strategies and metacognitive strategies are set forth with the purpose of giving some enlightenment to second language learning and language teaching.

\section{Theoretical Background}

\subsection{Theory of Cognition}

Cognitive theory is a learning theory of psychology that attempts to explain human behavior by understanding the thought processes. Cognitive theory focuses on the use of memory, thinking, reflection that are not necessarily reflected in the overt behavior changes. After 60's in the 20th century, the cognitive psychology becomes current. In cognitive theory, the learning process is a process of cognition structure's organization and reorganization. The essence of learning lies in an active formation of cognition structure, and has a continuous division and integration of previous cognition structure. They emphasize that new learning material and the learners' original cognition structure associate in a certain way or a certain situation, then the new learned knowledge and old knowledge will have an interaction, until the new material has its real meaning in the learner's head. It regards language learning not as a human behavior, but as an internal linguistic-processing ability of human individual. It gives importance to the learners' active part in the process of using and learning the language. In a cognitive approach, the learner is seen as an active participant in the learning process, using various mental strategies in order to sort out the system of the language to be learned. 


\subsection{Theory of Learning: Behaviorism}

Behavioral psychology claims to have tapped the secrets of all human learning, including language learning. Behaviorism, like structural linguistics, is another anti-mentalist, empirically based approach to the study of human behavior. To the behaviorist, the human being is an organism capable of a wide repertoire of behaviors. The occurrence of these behaviors is dependent upon three crucial elements in learning a stimulus, which serves to elicit behavior; a response triggered by a stimulus; and reinforcement, which serves to mark the response as being appropriate (or inappropriate) and encourages the repetition (or suppression) of the response in the future. Reinforcement is a vital element in the learning process, because it increases the likelihood that the behavior will occur again and eventually become a habit. To apply this theory to language learning is to identify the organism as the foreign language learner, the behavior as verbal behavior, the stimulus as what is taught or presented of the foreign language, the response as the learner's reaction to the stimulus, and the reinforcement as the extrinsic approval and praise of the teacher or fellow students or the intrinsic self-satisfaction of the target language use. Language mastery is represented as acquiring a set of appropriate language stimulus-response chains (Richards \& Rodgers, 2000).

\section{Factors Influencing Language Learning}

\subsection{Motivation}

Motivation is most frequently used in the educational contexts, and more considerations should be taken to the aspects of motivation. Motivation is responsible for determining human behavior by energizing it and giving it direction, and it is defined by many linguists. According to Dornyei and Otto (1998, p. 47), motivation can be defined as "the dynamically changing cumulative arousal in a person that initiates, directs, coordinates, amplifies, terminates, and evaluates the cognitive and motor processes, whereby initial wishes and desires are selected, prioritized, operationalized and (successfully or unsuccessfully) acted out" (Dornyei \& Otto, 1998, p. 65). Keller (1983, p. 389) defines motivation as "the choices people make as to what experiences" or defines motivation as "the choices people make as to what experiences or goals they will approach or avoid and the degree of effort they will exert in that respect".

\subsection{Aptitude}

Aptitude refers to the ability to learn the second language in an academic classroom. The Modern Language Aptitude Test (MLAT) broadly speaking requires the student to carry out L2 learning on a small scale. It incorporates four main factors that predict a student's success in the classroom (Carroll, 1981). These are:

- Phonemic coding ability: how well the student can use phonetic script to distinguish phonemes in the language.

- Grammatical sensitivity: whether the student can pick out grammatical functions in the sentence.

- Inductive language learning ability: whether the student can generalize patterns from one sentence to another.

- Rote learning: whether the student can remember vocabulary lists of foreign words paired with translations.

The Modern Language Aptitude Test is more or less purpose-designed for classroom learners, and should be taken as a method to evaluate learners' linguistic competence.

\subsection{Self-Confidence}

Self-confidence is an attitude which allows individuals to have positive yet realistic views of themselves and their situations. Self-confidence is one of the most important psychological elements for learners to get good learning results. People with self-confidence believe in their own abilities and have a general sense of control over their behaviors. Learners with great self-confidence generally have great self-belief and good images, and have great chances to succeed in foreign language learning. A self-confident person will remain positive and active though they fail to meet their expectations. People who do not have confidence usually depend too much on others for approval because they don't feel good about themselves. People with self-confidence dare to communicate with foreigners in foreign language in that they don't mind making mistakes and being laughed at by others. On the contrary, those less self-confident people tend to avoid taking risks because they are afraid of failure. They usually tend to look down upon themselves and in their mind it is not easy to be successful. 


\section{Suggestions for Language Teaching}

\subsection{Teaching Strategies on Motivation}

a) The teacher may establish appropriate goals and objectives in teaching English. The major goal of second language teaching should be to enable learners to use English effectively, and as far as possible accurately, in communication. Worthwhile and immediate objectives can give the learners satisfaction and a sense of success. Therefore, the teacher should try to make a careful plan about the classroom activities which are related to students' needs, interests and aspirations. Topics which can motivate students in class such as films, music and sports are recommended to proposed to the students.

b) It is very necessary for the teacher to create conditions and opportunities for learners to participate in class. A good design of a course should be dynamic, involving the learners in varied activities and interactions. The teacher must keep in mind that a positive atmosphere, a careful lesson design and various activities are bound to motivate students and develop their potential abilities. Students are willing to present themselves actively in class under such circumstances and they will not feel frustrated or depressed. Moreover, the teacher's encouragement and praise are also essential for the learners to make rapid progress in language learning.

\subsection{Teaching Strategies on Aptitude}

Cook (2002) proposes that the problem for language teachers is what to do once the students have been tested for academic learning aptitude. There are at least three possibilities:

1) Select students who are likely to succeed in the classroom and bar those who are likely to fail. This would, however, be unthinkable in most settings with open access to education.

2) Stream students into different classes for levels of aptitude, say high-flyers, average, and below average. The graded Objectives Movement in English, for instance, set the same overall goals for all students at each stage but allowed them different periods of time for getting there. Aptitude is then related to the speed with which students reach the final stage. Attitude then affects the number of aspects they are examined on at the final stage.

3) Provide different teaching for different types of aptitude with different teaching methods and final examinations. This might lead to varied exercises within the class, to parallel classes, or to self-directed learning. In most educational establishments this would be a luxury in terms of staffing and accommodation, however desirable.

In addition, for achievement of developing good language learners, the teacher is required to provide students with ample interactive learning activities, to relate students' prior knowledge and experience to learning of new language, to make best use of students' strengths in receptive skills and thinking ability to ensure the quantity of knowledge input, and to promote students' quality of output of linguistic knowledge through the development of students' overall abilities such as analysis, memory, productive and receptive skills, communicative skills, and learning strategies, etc.

\subsection{Teaching Strategies on Self-Confidence}

Students who are lack of self-confidence will not usually answer the teacher's questions actively. They dare not present themselves in front of the whole class because they are afraid of making mistakes. What's more, they often keep silent in group discussion. In light of these weaknesses of self-contemptuous students, the teacher ought to take some measures to eliminate their sense of inferiority. The measures are listed as follows.

a) The teacher may arrange some tasks that are suitable for those students who are short of self-confidence to finish according to their own characteristics and individual differences. In this way, appropriate learning objectives are to be made so that the students are able to accomplish their tasks with ease. The successful experience of the fulfillment of a task may make students feel confident. The more successful practice a student gets, the less anxious he will be. Furthermore, the teacher has to guide the students to draw a lesson from their unsuccessful learning experiences and then make progress. The teacher should pay attention to taking advantage of interesting teaching methods to inspire students to learn with initiative and enthusiasm. It is necessary for the teacher to create opportunities for the students to get successful practice so that they will have confidence in their learning ability.

b) The teacher ought to take humanistic teaching methods to proceed their teaching. Encouragement and inspiration are needed to reduce students' frustration in their learning activities. A warm and loving teacher is likely to be more popular with the students. In fact, only with confidence and courage can a student struggle to work harder. The student who is often being blamed by the teacher for his faults is inclined to be disappointed at their teacher and lose interest in language learning. Therefore, first of all, the teacher should respect the students. 
He should realize the individual differences between students and give them more care rather than criticism. A teacher's attention, concern and expectation play a very important role in the cultivation of the students' confidence. The teacher needs to communicate with their students constantly and get to know each student's emotional needs so that he can modify his teaching methods to satisfy each student's requirement. The strengthening of a learner's self-confidence is helpful to promote the development of his cognitive abilities.

\section{Learning Strategies}

It is important for the teachers to help learners acquire and develop learning strategies which are useful for learners to enhance their ability to learn independently. Rubin defines learner strategies as including: any set of operations, steps, plans, routines used by the learner to facilitate the obtaining, storage, retrieval and use of information, ...that is, what learners do to learn and do to regulate their leaning (Rubin, 1987). The most frequently used learning strategies are cognitive strategies and metacognitive strategies. Cognitive strategies are thought processes used directly in learning which enable learners to deal with the information presented in tasks and materials by working on it in different ways. Analogy, memorization, repetition, writing things down, and inferencing are examples of cognitive strategies. Metacognitive strategies involve planning for learning, thinking about learning and how to make it effective, self-monitoring during learning, and evaluation of how successful leaning has been after working on language in some way (Hedge, 2002).

Oxford (1990a) developed this Strategy Inventory for Language Learning (SILL, ESL/EFL Student Version), which contains six categories:

1) memory strategies for storing and retrieving new information;

2) cognitive strategies for manipulating and transforming learning materials;

3) compensation strategies for overcoming deficiencies of knowledge in language;

4) metacognitive strategies for directing the learning process;

5) affective strategies for regulating emotions; and finally;

6) social strategies for increasing learning experience with other people.

\subsection{The Present Learning Situation of University Students}

Most of the language learners lack theories of learning strategies and know little about the types of learning strategies. Learners often wonder how to learn English well and what kind of methods they should take. Many learners intend to improve their English level by means of memorizing new words, reciting texts and doing more exercises. These learning strategies are not efficient enough for learners to get good learning outcome. Over half of the learners don't have definite learning goals and learning plans. They just passively acquire knowledge according to the teacher's teaching plan and requirements. Only a few of the students realize the importance of using self-monitoring in their learning process. They seldom rethink their learning behaviors and evaluate their learning effects.

\subsection{Suggestions of Learning Strategies}

Research into learner strategies has made an important contribution to the field of ELT by highlighting the possibility of learners becoming more self-reliant in their learning, and by generating discussion of how learners can be trained to take on more responsibility for their learning. Much of the research has tried to establish whether it is possible to facilitate leaning through the use of certain strategies, or whether learners can modify their strategies and learn new, more effective ones. Learners' learning strategies concerning learners' factors can be trained from the perspectives of cognitive strategies and metacognitive strategies.

\subsubsection{Training Cognitive Strategies}

In the traditional classroom, the teacher is expected to give a detailed description of the usage of new words. However, students may learn to equip themselves with such techniques as using clues in the text to guess the word meaning or getting the word's meaning by looking up the dictionary. Students are encouraged to employ some other cognitive strategies, for example, use textbook as a resource to search for sentence patterns and grammar rules by analyzing the language data it offers. Orchestrating language production and comprehension with body movement and physical actions is thought to provide the conditions for success in language learning. The teachers' design of the classroom tasks can offer the students full play of their intellectual potential. Through a large amount of information input of language learning, students are provided with a new context and a lot of new knowledge, which offers students materials for them to conduct their imaginative thinking from the multiple perspectives. From the point of view of information processing, with more information input, the students need 
to process more information. At the same time, with more information output, students' thinking ability is cultivated to be smooth and flexible.

\subsubsection{Training Metacognitive Strategies}

Oxford (1990) holds the concept that metacognitive strategies includes the categories of centring learning (for example, overviewing, paying attention); arranging and planning learning (for example, setting goals and objectives, organizing, and seeking out practice opportunities); and evaluating learning (for example, self-monitoring). "Self-assessment is an attractive alternative or addition to traditional forms of assessment for the classroom teacher. It is a particular type of metacognitive strategy which deserves special attention. It aims to help students develop those characteristics of the 'good language learner' which involve the ability to assess their own performance and the ability to be self-critical" (Hedge, 2000, p. 94). The students may assess their learning process by rethinking the questions: did what I do really do good to English learning? Am I satisfied with my performance? In what way should I improve myself? These rethinking behaviors will help students to be more aware of their individual progress both in the language acquisition and in their learning abilities. Self-assessment personalizes the process of monitoring development, and when students have been gradually introduced to the idea of collaborative work and can respond to it productively, this too can be used in assessment activities, as in the second stage of the activity. The ability to assess one's own learning becomes particularly important for any student who wants to work independently with resources in some kind of self-access or open leaning center. Students who employ self-access strategy benefit a lot. They can use it in their own way and monitor their own progress. Once students have been prepared in the necessary skills and oriented to the possibilities offered by self-access learning, they can be supported in creating their own self-study programmes, working on individual needs and interests, and monitoring their own progress. The success of self-access learning will depend on the thoroughness with which students have been prepared through a careful process of learner training.

\section{Conclusion}

English teaching should not be separated from the perspective of learner's overall qualities. In addition to learners' intellectual factors, more focus should be taken on the various characteristics of individuals from the psychological respects. Students can facilitate language learning through the use of certain strategies and by modifying their learning strategies, they can find some new and more effective ones to improve their learning effects. The paper presents to the readers that different learners tend to use different strategies, and the strategies used by some good language learners are worth mentioning. Some weak points in English language teaching reveal that it is urgent for the teacher to improve classroom teaching and students' learning strategies need to be modified so as to get a better learning result.

\section{References}

Carroll, J. B. (1981). Twenty-five years of research on foreign language aptitude. In K. C. Diller (Ed.), Individual Differences and Universals in Language Learning (pp. 83-118). Rowley, MA: Newbury House,

Dornyei, Z., \& Otto, I. (1998). Motivation in action: A process model of L2 motivation, Working papers in Applied Linguistics (Vol. 4, pp. 43-69). London: Thames Valley University.

Hedge, T. (2000). Teaching and Learning in the Language Classroom (p. 94). Oxford: Oxford University Press.

Hedge, T. (2002). Teaching and Learning in the Language Classroom (p. 78). Shanghai: Shanghai Foreign Language Education Press.

Keller, J. M. (1983). Motivational design of instruction. In C. M. Reigelruth (Ed.), Instructional design theories and models: An overview of their current status (pp. 383-434). Lawrence Erlbaum, NJ: Hillsdale.

Oxford, R. L. (1990a). Language Learning Strategies: What Every Teacher Should Know Boston. MA: Heinle \& Heinle.

Richards, J. C., \& Rodgers, T. S. (2000). Approaches and Methods in Language Teaching (p. 50). Beijing: Foreign Language Teaching and Research Press.

Rubin, J. (1987). Learner strategies: Theoretical assumptions, research history and typology. In A. Wenden, \& J. Rubin (Eds.), Learner Strategies in Language Learning (pp. 15-29). New Jersey: Prentice Hall.

Vivian, C. (2000). Second Language Learning and Language Teaching. Foreign Language Teaching and Research Press. 


\section{Copyrights}

Copyright for this article is retained by the author(s), with first publication rights granted to the journal.

This is an open-access article distributed under the terms and conditions of the Creative Commons Attribution license (http://creativecommons.org/licenses/by/3.0/). 